\title{
An inshore-offshore sorting system revealed from global classification of ocean litter
}

\author{
Carmen Morales-Caselles $\mathbb{1}^{1}$, Josué Viejo, Elisa Martí', Daniel González-Fernández $\mathbb{D}^{1}$, \\ Hannah Pragnell-Raasch², J. Ignacio González-Gordillo', Enrique Montero³, Gonzalo M. Arroyo ${ }^{1}$ 1, \\ Georg Hanke ${ }^{4}$, Vanessa S. Salvo5, Oihane C. Basurko ${ }^{6}$, Nicholas Mallos ${ }^{7}$, Laurent Lebreton ${ }^{8}$, \\ Fidel Echevarría1, Tim van Emmerik ${ }^{1}{ }^{9}$, Carlos M. Duarte ${ }^{10}{ }^{10}$, José A. Gálvez ${ }^{1}$, Erik van Sebille ${ }^{10}{ }^{11}$, \\ François Galgani ${ }^{12}$, Carlos M. García', Peter S. Ross ${ }^{13}$, Ana Bartual', Christos loakeimidis ${ }^{14}$, \\ Gorka Markalain ${ }^{1}{ }^{1}$, Atsuhiko Isobe ${ }^{15}$ and Andrés Cózar ${ }^{1}{ }^{1 凶}$
}

The surge of research on marine litter is generating important information on its inputs, distribution and impacts, but data on the nature and origin of the litter remain scattered. Here, we harmonize worldwide litter-type inventories across seven major aquatic environments and find that a set of plastic items from take-out food and beverages largely dominates global litter, followed by those resulting from fishing activities. Compositional differences between environments point to a trend for litter to be trapped in nearshore areas so that land-sourced plastic is released to the open ocean, predominantly as small plastic fragments. The world differences in the composition of the nearshore litter sink reflected socioeconomic drivers, with a reduced relative weight of single-use items in high-income countries. Overall, this study helps inform urgently needed actions to manage the production, use and fate of the most polluting human-made items on our planet, but the challenge remains substantial.

$\mathrm{T}$ he mass consumption and accelerated discard of human-made products is posing an acute disposal problem at a global scale. Metal, textile, glass, paper, ceramic, rubber and, in particular, plastic items accumulate in shorelines, water and seafloors worldwide ${ }^{1}$. The concerning increase of plastics in the oceans is an undesirable outcome of the prevailing produce-use-dispose linear economic model ${ }^{2,3}$. In 2010, total plastic waste generated was estimated to equal the global production of plastic materials, with around 8 million metric tons of plastic waste entering the ocean from land-based sources ${ }^{4}$.

While an onrush of initiatives to combat marine litter spreads around the world, the necessary information to guide these actions remains limited. A global picture is emerging of the distribution of plastic fragments on the ocean surface, characterized by great mid-ocean accumulation zones ${ }^{5,6}$. Yet, plastic floating on the surface accounts for only a tiny fraction of the estimated annual emissions into the ocean ${ }^{5-7}$, and large-sized items are underrepresented in the trawling plankton nets commonly used to measure floating debris ${ }^{8}$. Macro-litter, items larger than a few centimetres, is often studied using inventory approaches, which count litter items by type $e^{9,10}$. However, macro-litter inventories are underused, due in large part to the differences in the classification methods across studies ${ }^{11}$.

In this article, we conduct a global classification of macro-litter by type of product. To do this, we harmonized inventories from scientific surveys and civil society networks to create a database of millions of litter items found across seven major aquatic environments, ranging from rivers to shorelines and the open ocean, and from the surface to the seafloor (Supplementary Fig. 1 and Supplementary Table 1). Due to a lack of standardized sampling protocols, we do not track litter items across ecosystems on a mass load basis. Instead, our approach combines datasets gathered from multiple locations and habitats by harmonizing item categories and using relative proportions (Supplementary Fig. 2). In this way, we seek to provide a first overview of the origin, transport and ultimate fate of litter in the global ocean.

\section{Global classification of litter}

More than 12 million litter items retrieved from 7 major environments globally were classified according to their material composition, type of product and probable origin. This analysis confirmed, on a global and multi-ecosystem scale, the overwhelming prevalence of plastic items (Fig. 1). On average, $80 \%$ of the items were made of plastic (standard deviation across seven environments $\pm 18 \%$ ), followed by metal $(7 \% \pm 7 \%)$, glass $(5 \% \pm 6 \%)$ and fabric $(3 \% \pm 3 \%)$. The largest share of plastic was found in surface waters $(95 \%)$, followed by shorelines ( $83 \%$ ). Below the surface, the proportion of plastic in total litter increased progressively from $49 \%$ on riverbeds to $64 \%$ on nearshore bottoms and $77 \%$ on deep seafloors.

'Departamento de Biología, University of Cadiz and European University of the Seas (SEA-EU), Instituto Universitario de Investigación Marina (INMAR), Puerto Real, Spain. ${ }^{2}$ Project Aware, Dive Against Debris, Melbourne, Victoria, Australia. ${ }^{3}$ Asociación Proyecto Ecopuertos, Cádiz, Spain. ${ }^{4}$ European Commission Joint Research Centre, Directorate D - Sustainable Resources, European Commission, Ispra, Italy. ${ }^{5}$ Posidonia Green Project, Barcelona, Spain. ${ }^{6}$ AZTI Marine Research, Basque Research and Technology Alliance (BRTA), Pasaia, Spain. ${ }^{7}$ Ocean Conservancy, Portland, OR, USA. ${ }^{8}$ The Ocean Cleanup, Rotterdam, Netherlands. ${ }^{~ H}$ ydrology and Quantitative Water Management Group, Wageningen University, Wageningen, Netherlands. ${ }^{10}$ Red Sea Research Centre (RSRC) and Computational Bioscience Research Center (CBRC), King Abdullah University of Science and Technology, Thuwal, Saudi Arabia. "Institute for Marine and Atmospheric Research Utrecht, Utrecht University, Utrecht, Netherlands. ${ }^{12}$ IFREMER (French Institute for Research and Exploitation of the Sea), Immeuble Agostini, Z.I. Furiani, Bastia, France. ${ }^{13}$ Department of Earth, Ocean and Atmospheric Sciences, University of British Columbia, Vancouver, British Columbia, Canada. ${ }^{14}$ UNEP/ Mediterranean Action Plan, Barcelona Convention Secretariat, Athens, Greece. ${ }^{15}$ Research Institute for Applied Mechanics, Kyushu University, Kasuga, Japan.凶e-mail: carmen.morales@uca.es; andres.cozar@uca.es 

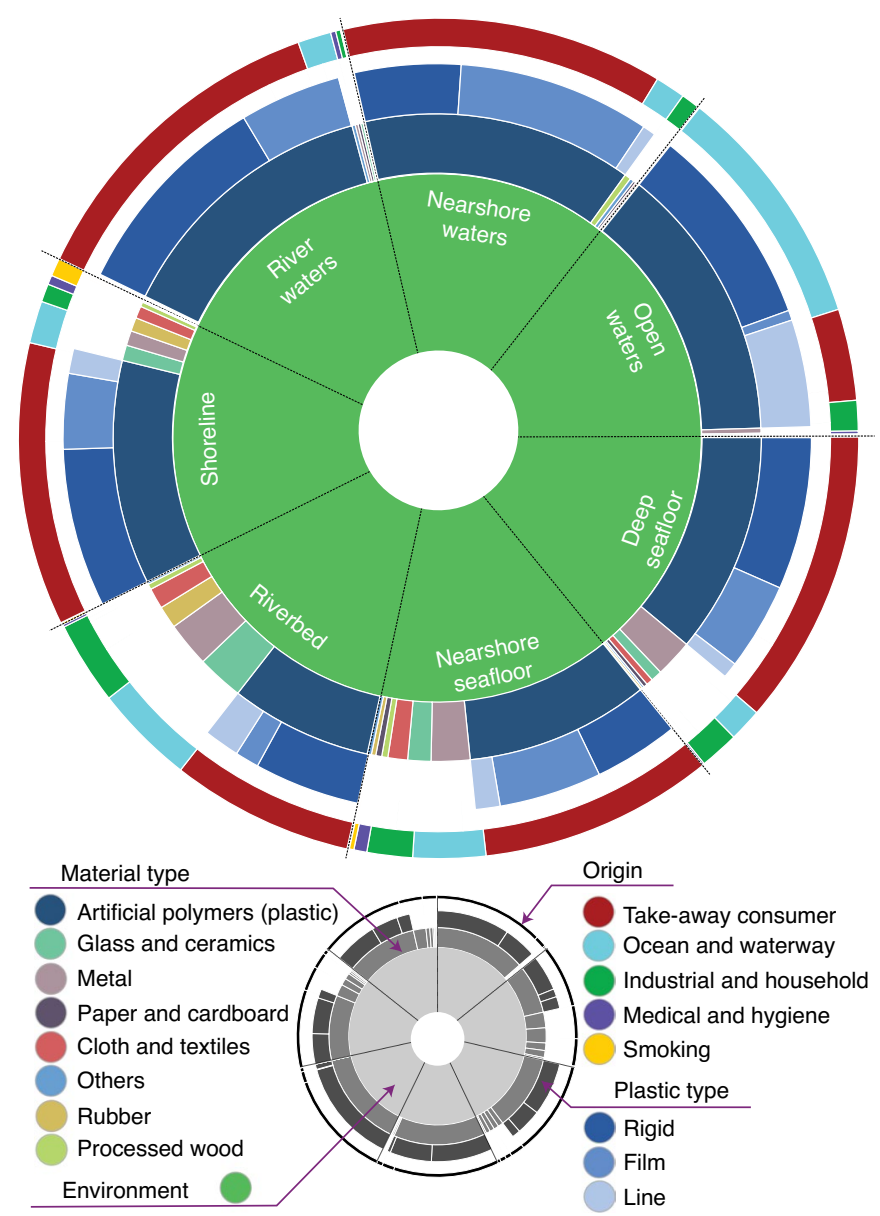

Fig. 1 | Material, plastic type and probable origin of the litter found in the seven major aquatic environments at a global scale. Each ring shows seven segments, each corresponding to one of the environments investigated (titles are in the inner green ring). Concentric rings represent material types, plastic types and origin from the inside out, respectively. The relative sizes of colour portions in each ring segment represent the relative counts per environment. See the legend for the meaning of colours and chart structure. Smoking-related items include tobacco pouches, cigarette packages and lighters but not cigarette filters and cigar tips.

In terms of litter origins, take-out consumer items (mainly plastic bags and wrappers, food containers and cutlery, plastic and glass bottles, and cans) made up the largest share across environments (from $50 \%$ to $88 \%$ ), except for the open ocean, where most of the items resulted from ocean-based activities (66\%; Fig. 1). The largest share of items originating from household and industrial activities was observed in riverbeds (22\%). Items with a medical and/or hygienic origin, widely attributed to toilet flushing ${ }^{12}$, were more prevalent in nearshore seafloors (4\%). Smoking-related items (tobacco pouches, cigarette packages and lighters) were most abundant on shorelines (5\%), even though the widespread cigarette filters and cigar tips were excluded from our analysis due to their small size and inconsistent sampling across inventories (Methods).

Of the 112 litter categories used in our analysis, 10 types of products accounted for three-quarters of all litter items found globally (Fig. 2 and Supplementary Fig. 3). The top ten products, in descending order, were bags ( $14 \% \pm 8 \%$ across environments), plastic bottles $(12 \% \pm 5 \%)$, food containers and cutlery $(9 \% \pm 13 \%)$, wrappers $(9 \% \pm 14 \%)$, synthetic ropes $(8 \% \pm 11 \%)$, fishing-related items (for example, strings, threads, buoys; $8 \% \pm 8 \%$ ), plastic caps and lids
$(6 \% \pm 5 \%)$, industrial packaging $(3 \% \pm 3 \%)$, glass bottles $(3 \% \pm 4 \%)$ and beverage cans $(3 \% \pm 4 \%)$.

Plastic bags appeared among the two highest positions of the rankings for all the environments, with the exception of riverbeds and open waters (top seven and eight, respectively). Plastic bottles consistently ranked among the top five items in every environment and were particularly frequent on deep seafloors (23\%). Wrappers and packaging were abundant in coastal environments and relatively scarce in the open ocean. Plastic food containers and cutlery were the most-reported items found in river waters and were very common on shorelines.

Meanwhile, synthetic ropes, strings, threads, buoys and nets represented the majority of items found in open waters (61\% of the total items). These items tend to be part of fishing gear that has been lost or discarded ${ }^{13}$. In fact, the composition of litter in the open ocean showed the largest dissimilarity compared with the other aquatic environments (Supplementary Fig. 4).

Beverage cans were among the top ten litter items on seabeds, especially on deep bottoms (10\%). Glass bottles were highly common in riverbeds. Finally, industrial packaging items were prevalent in river waters as well as offshore areas (both water and seafloor), probably due to distinct land-based (industry, agriculture) and ocean-based (shipping) sources, respectively.

The database assembled here provides a cross-ecosystem view of the nature and origin of ocean litter. There are local datasets that report worrying abundances of sanitary litter in urban riv$\mathrm{ers}^{14}$ or agricultural plastic waste in areas of the Mediterranean ${ }^{15}$, but our global analysis clearly points to consumer activities as the main sources of marine litter, followed by sea-based activities. It is widely cited that about $80 \%$ of marine litter originates on land, and the remaining $20 \%$ is attributed to sea-based sources. Strikingly, this figure lacks empirical support ${ }^{4,16}$. By combining all the items in our database directly linked to marine activities (Supplementary Table 4), we obtain an average contribution across environments of $22 \%$ ( $\pm 21 \%)$, very close to the oft-quoted $20 \%$, with the caveat that our account should be regarded as a minimum. Only items clearly linked to fishing, aquaculture or shipping (mainly fishing gear) were included in our estimate, although take-out, industrial or any other items retrieved at sea (for example, clothes) might also come from marine activities or be disposed of by crew and passengers from vessels and ocean platforms of all types ${ }^{17}$. In any case, sea-based sources are shown to play an important role in marine litter pollution.

Interestingly, film-type plastics, such as bags and wrappers, were highly prevalent in nearshore areas $(58 \%$ of plastic items in seafloors and $62 \%$ in water), while their contribution to total plastic macro-litter in the open ocean was extremely low (3\%) (Fig. 1). Film plastics made of polymers denser than seawater (for example, polyethylene terephthalate) are likely to deposit near the point of entry into the sea (unless they are foamed or have trapped air $)^{18}$. However, most of the film plastic is used for lightweight single-use products, and it is generally made of low-density polymers (polyethylene, polypropylene) that float in water ${ }^{19,20}$. These plastics could be expected to be transported long distances along the ocean surface by wind and currents, but our results do not support the idea of an efficient transport from land to open waters for these materials. Buoyant plastics can sink after being ballasted by the accretion of sediments, algae and other organisms or entangled with other items. Film-like items show large surfaces available to support biofouling organisms and become entangled or snagged, being especially prone to vertical transport and rapid deposition on the seafloor ${ }^{18,21}$. Therefore, the prevalence of films in nearshore environments could be explained on the basis of substantial production and likely frequent dumping of bags and wrappers on land, along with their retention and eventual sinking close to shore. 


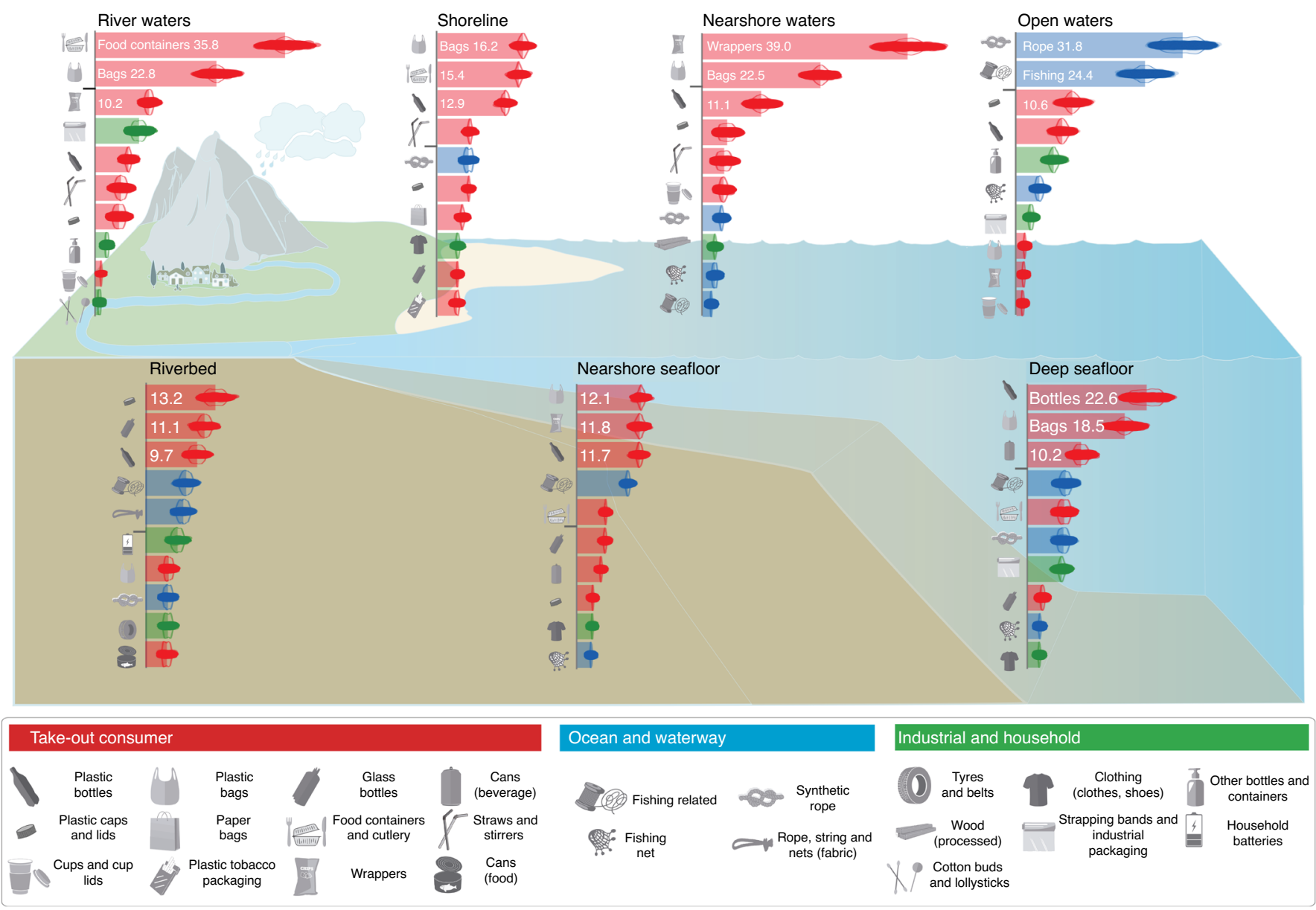

Fig. 2 | Top ten litter items in aquatic environments. Bars show mean percentages per environment, while the darker-coloured areas and lines around the means show the individual data outputs $(n=10,000)$ and the distribution beanplot, respectively. Uncertainties of results were quantified through 10,000 Monte Carlo iterations in each environment ${ }^{8}$. Bar colour relates to potential origin (take-out consumer, industrial and household, ocean and waterways). Items above the horizontal line marks in the rankings comprise, at least, $50 \%$ of the total items identified. Only identifiable items were accounted for in the rankings: river waters $(n=1,950,571)$, riverbed $(n=25,410)$, shoreline $(n=9,864,628)$, nearshore waters $(n=13,130)$, open waters $(n=10,087)$, nearshore seafloor $(n=615,949)$ and deep seafloor $(n=70,302)$.

\section{An inshore-offshore sorting system of floating litter}

Litter composition at the sea surface shifts from take-out consumer items nearshore to a dominance of fishing-related items offshore, reflecting land- and ocean-based inputs of macro-litter, respectively (see Fig. 3 for illustrative samples from nearshore and offshore areas). Much of the floating macro-litter entering the ocean from land must be retained within coastal environments, possibly combining recurrent episodes of beaching, settling and resurfacing and delaying the incorporation of plastic into the open-ocean accumulation zones. This conclusion aligns with that derived from the age distribution of ocean plastic and the finding of decades-old objects in offshore waters ${ }^{22}$.

The recirculation of floating macro-litter into coastal environments is not in conflict with the accumulation of floating plastic debris reported in the subtropical gyres of the open ocean ${ }^{5,6}$. Global particle-tracking models agree that litter accumulating in the subtropical gyres is due primarily to the Ekman transport and surface convergence of debris into the centres of the ocean basins ${ }^{23-25}$. However, surface-transport models that account for the portion of the item emerged above the sea surface, as well as the depth at which the item submerges in the mixing layer, describe opposite delivery pathways (seaward and landward) depending on the object's buoyancy ${ }^{26,27}$.
Buoyancy and size as key features. The dependence of the surface transport of floating debris on its buoyant force may explain the segregation of litter along the ocean surface. Floating litter is sorted out in turbulent conditions induced by wave and wind, with some items more prevalent on the water surface (high-buoyancy litter) and others more susceptible to submerge into the mixing layer (low-buoyancy litter) ${ }^{28,29}$. Thus, highly buoyant items are more affected by the wave-driven Stokes drift and windage, which results in ejection from the oceanic accumulation zones and transport to shore and beaches ${ }^{8,26,30,31}$. By contrast, low-buoyancy litter would escape the wind and waves sweeping the ocean surface and have a greater likelihood of entering into the Ekman convergence to the great mid-ocean gyres $^{5-7,32}$.

The buoyant force of a floating item is strongly related to its volume. Thus, small-sized plastic fragments are a fundamental component of the low-buoyancy litter ${ }^{29}$. Previous studies have provided empirical support for the seaward transport of small plastic particles by using surface-trawling plankton nets to estimate the ratio between micro- and meso-plastic sizes $(<0.5 \mathrm{~cm}$ and from 0.5 to $5 \mathrm{~cm}$, respectively ${ }^{27,33}$. Here, we explore the size distribution of plastic debris, ranging from items as small as half a millimetre up to 1 metre, in both nearshore and offshore waters. 
a

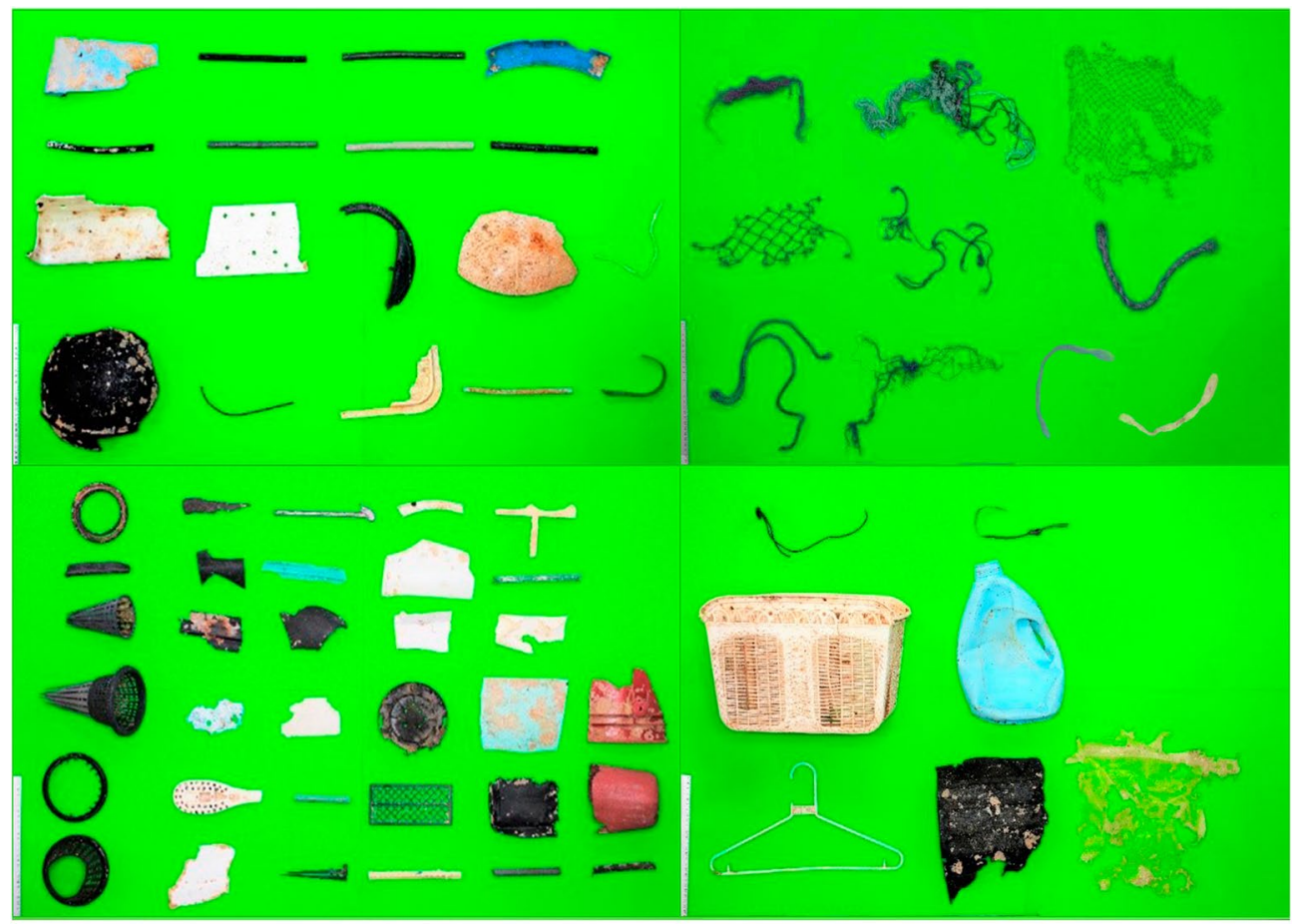

b

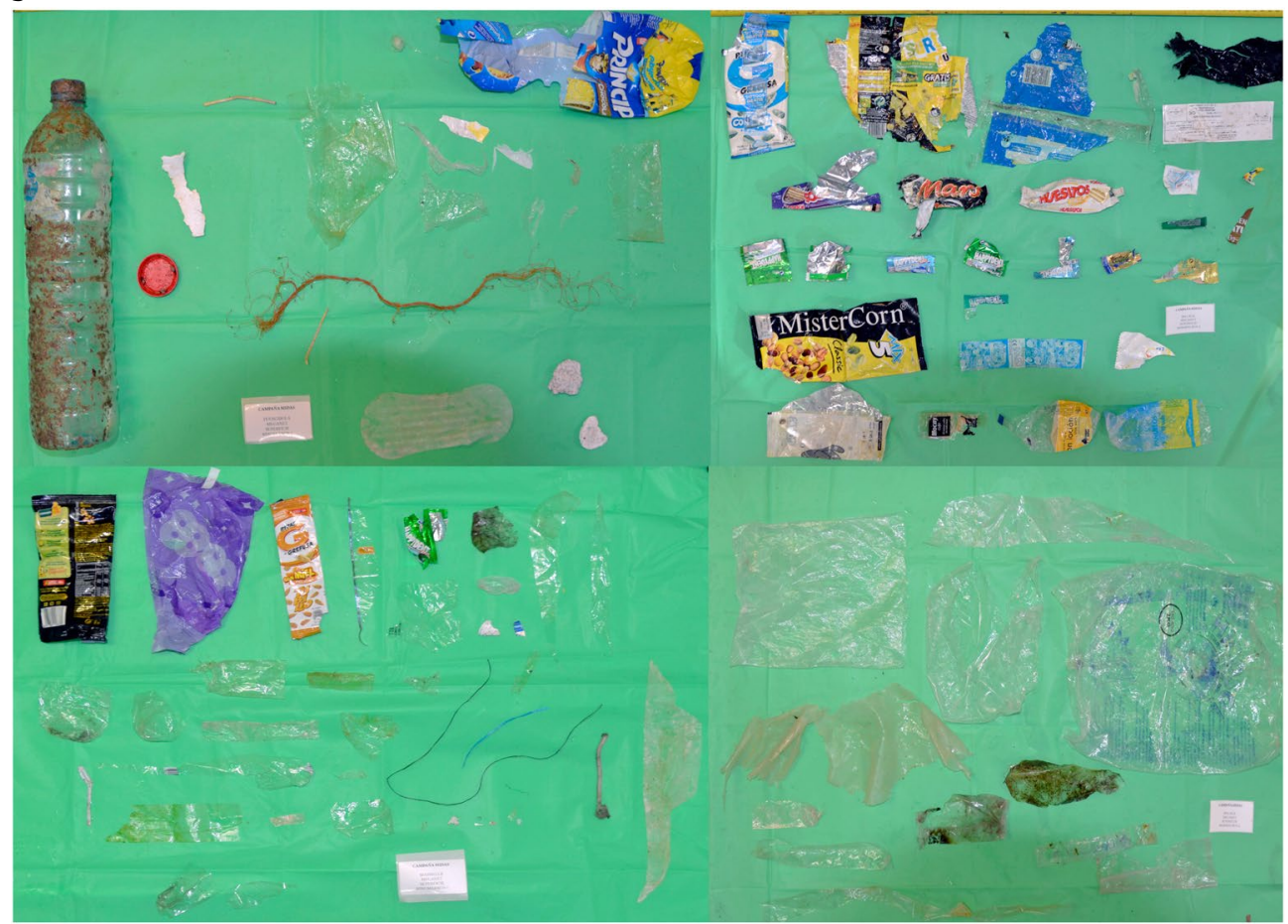

Fig. 3 | Samples collected with surface-trawling macro-nets from offshore and nearshore surface waters. a, Offshore samples showed a predominance of rigid-type plastics, household items (hangers, detergent containers and so on) and fishing-related items (spacers, pieces of net, fishing threads and so on). b, By contrast, nearshore samples showed a prevalence of film-type plastics, mainly wrappers, and cover/packaging-related items.

For all types of plastic (films, rigid and lines), we found small fragments to be notably more frequent in open-ocean accumulation zones, whereas large items were more prevalent in coastal waters (Supplementary Fig. 5). The analysis of floating litter, over four orders of magnitude in linear size, also fits with an inshore-offshore sorting system. That being said, more research is needed to validate our size-based findings, particularly in terms of spatial coverage. Given the importance of the information related to the plastic size, we advocate a global effort to investigate wider size distributions over more-extensive ocean areas as well as other environments, including seafloors and shorelines. Nearshore and deep seafloors, as depositional environments, are highly suited for assessing the size sorting at the surface ${ }^{34}$. 

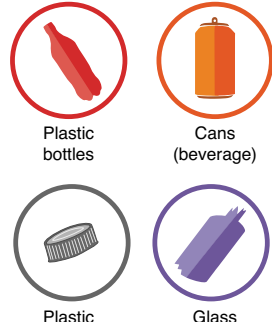
(beverage)

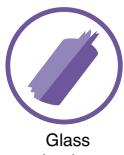

caps

bottles

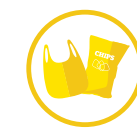

Plastic bags and wrappers industrial packaging

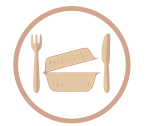

Food containers and cutlery

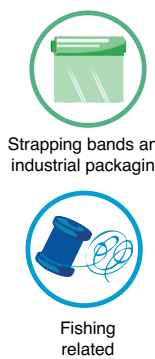

related

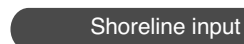

Nearshore input
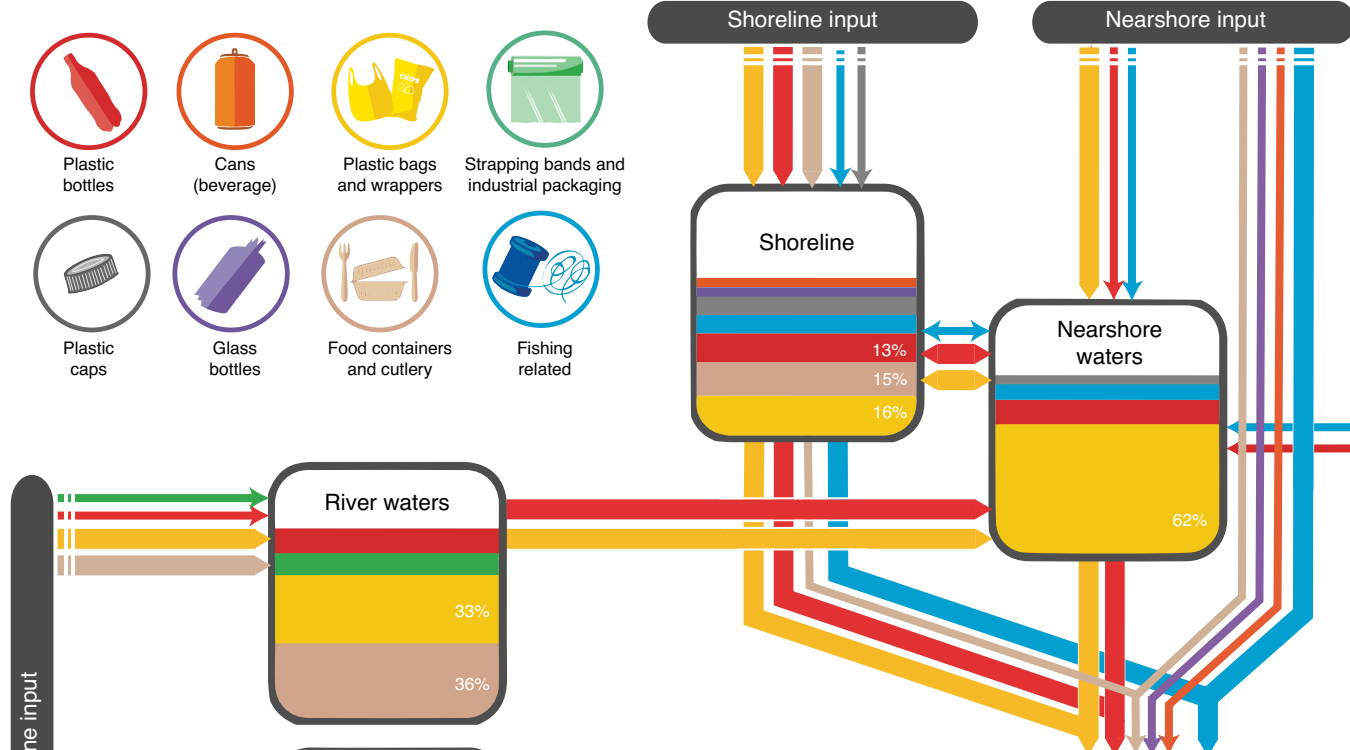

.
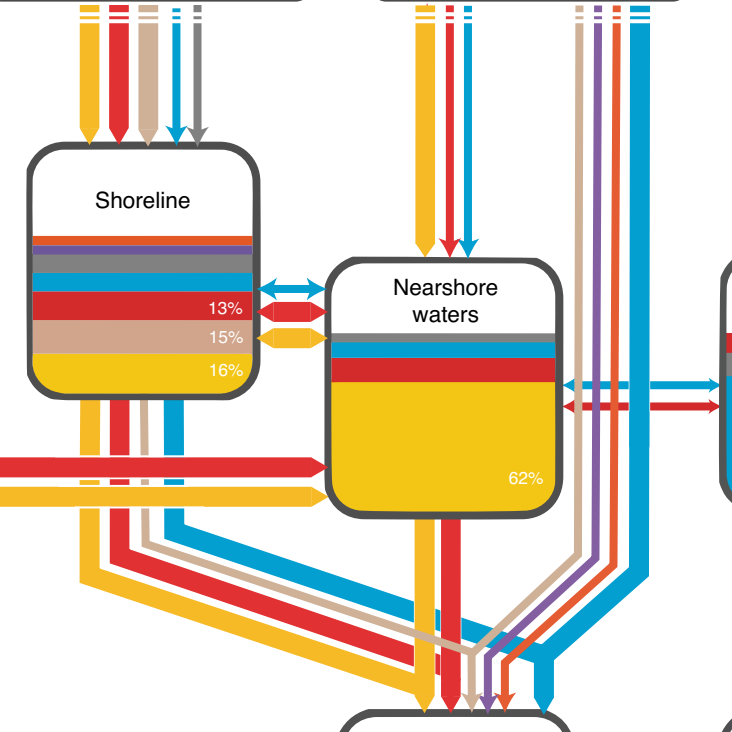

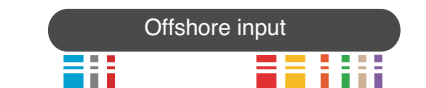

Open waters
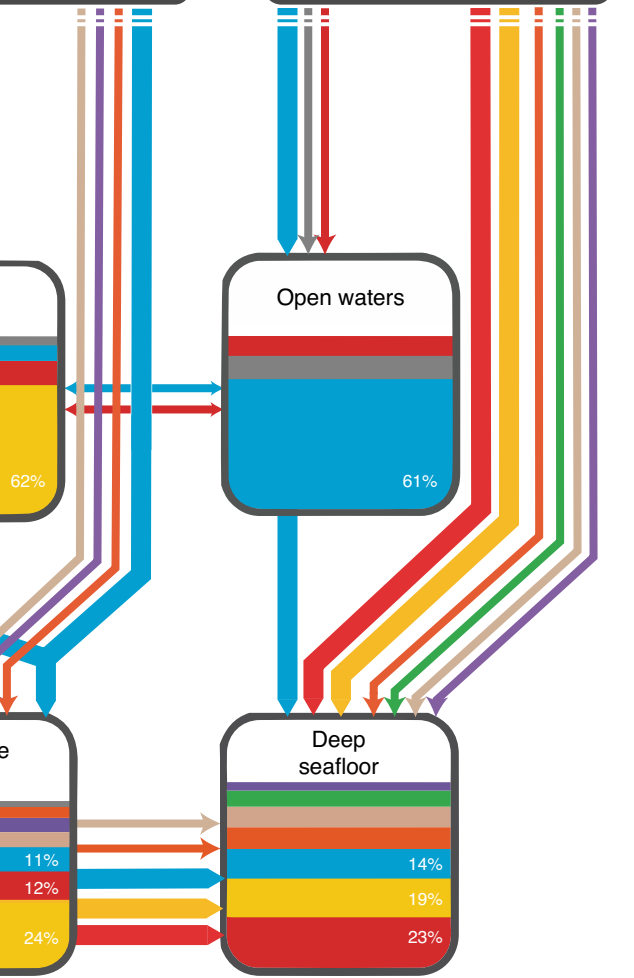

Deep seafloor

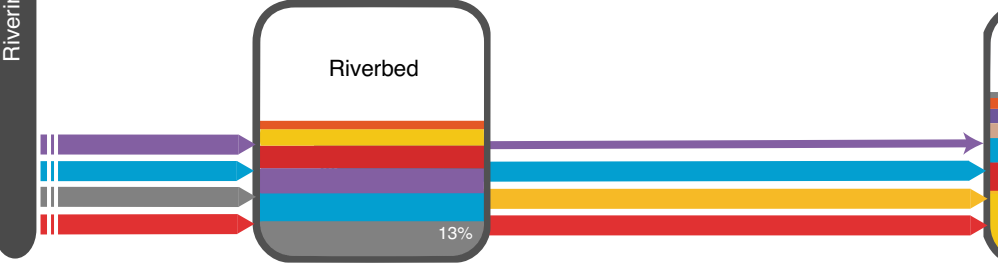

Fig. 4 | Conceptual model of the most likely predominant flows of the top litter items in the ocean. The arrows hypothesize the main connections among environments depicted as pools. The contribution in relative abundance into each environment is indicated with colour bars (see colour legend). White portions in the pools account for other items. Flows between environments were established systematically according to the contribution of each litter item to the source and the receiving reservoirs (Methods). Thick connectors indicate pathways with a greater contribution to the specific flow supplying each reservoir, regardless of the absolute magnitude of flows. Fishing-related items comprise synthetic ropes, strings, buoys, threads and nets.

While plastic degradation can occur throughout the ocean surface, shorelines are singled out as an important potential source of small fragments $\mathrm{s}^{22,35}$. The degradation of plastic items exposed at high-temperature conditions and the mechanical forces from wave breaking accelerate the cracking and fragmentation of plastic litter onshore $^{20,36}$, resulting in the generation of the small fragments that are then likely to be transported offshore.

Transport pathways of top items. On the basis of an illustrative flow diagram of ocean litter (Supplementary Fig. 6) and the relative proportions per environment, we propose an initial conceptual model of the most likely flows of top items (Fig. 4). The analysis captured the two major vertical pathways of litter delivery, to nearshore and offshore seafloors. On the surface, the horizontal connection between nearshore and offshore pathways occurs mainly through bottles and fishing-related items, which are actively transported across the ocean surface. Indeed, bottles and highly buoyant fishing gear (for example, buoys) often represent the most abundant items stranded on remote islands with limited on-site waste generation ${ }^{17,37}$. The bedload transport of a diversity of litter items from coastal to deep seafloor is well documented along canyons ${ }^{38}$, which act as deep conduits of litter. This path is likely to be important where major sources, such as large cities, are present near the mouths of the canyons, as reported in the Mediterranean ${ }^{39}$. Nevertheless, the diffuse vertical input from floating loads and sea-based sources also seems to play a major role in deep-sea littering (Fig. 4), as also suggested by the ubiquity of litter found on the vast seafloor ${ }^{38}$.

A more-complex picture. A global inshore-offshore sorting system of floating litter should result in high relative proportions of macro-plastic in coastal waters and micro-plastic in open waters (for example, Supplementary Fig. 5). However, this general pattern can be modified by the skewed distribution of plastic sources, size-selective sinks or other transport processes working on smaller spatial scales. First, we must note that most sources of marine micro-plastics (for example, sewage, onshore fragmentation) originate from land, which could lead to relatively high micro-plastic concentrations in nearshore areas ${ }^{35}$. Second, while highly buoyant plastic is transported across the ocean, the micro-plastic load gets reduced by the selective mechanisms of removal from the surface (for example, ballasting, ingestion) ${ }^{5}$. Furthermore, surface-transport mechanisms at scales smaller than the great subtropical gyres also act on the floating objects depending on their buoyancy ${ }^{40}$, inducing additional adjustments in the relative proportions of micro- and macro-plastics.

The transport of floating litter in the ocean depends on the buoyant force, a feature closely related to the item size ${ }^{29}$. However, the diversity of marine floating litter is poorly represented by a simple split into high- and low-buoyancy items, or into micro- and macro-plastics. Buoyant items show a wide range of sizes, shapes and materials ${ }^{41}$. Certain plastic materials (for example, Styrofoam) show very low density and a strong tendency to stay on the surface, even as small particles. Large-sized floating fishing nets often have a long underwater draft, being less affected by wind-driven transport processes sweeping the ocean surface and more likely trapped into the subtropical gyres ${ }^{8}$. By contrast, shapes including internal air volume (for example, empty bottles, buoys, Styrofoam crates) are especially prone to windage, showing the highest beach delivery rates ${ }^{30,31}$.

The inshore-offshore sorting system focuses on the floating litter and ocean surface transport. However, the subsurface transport 


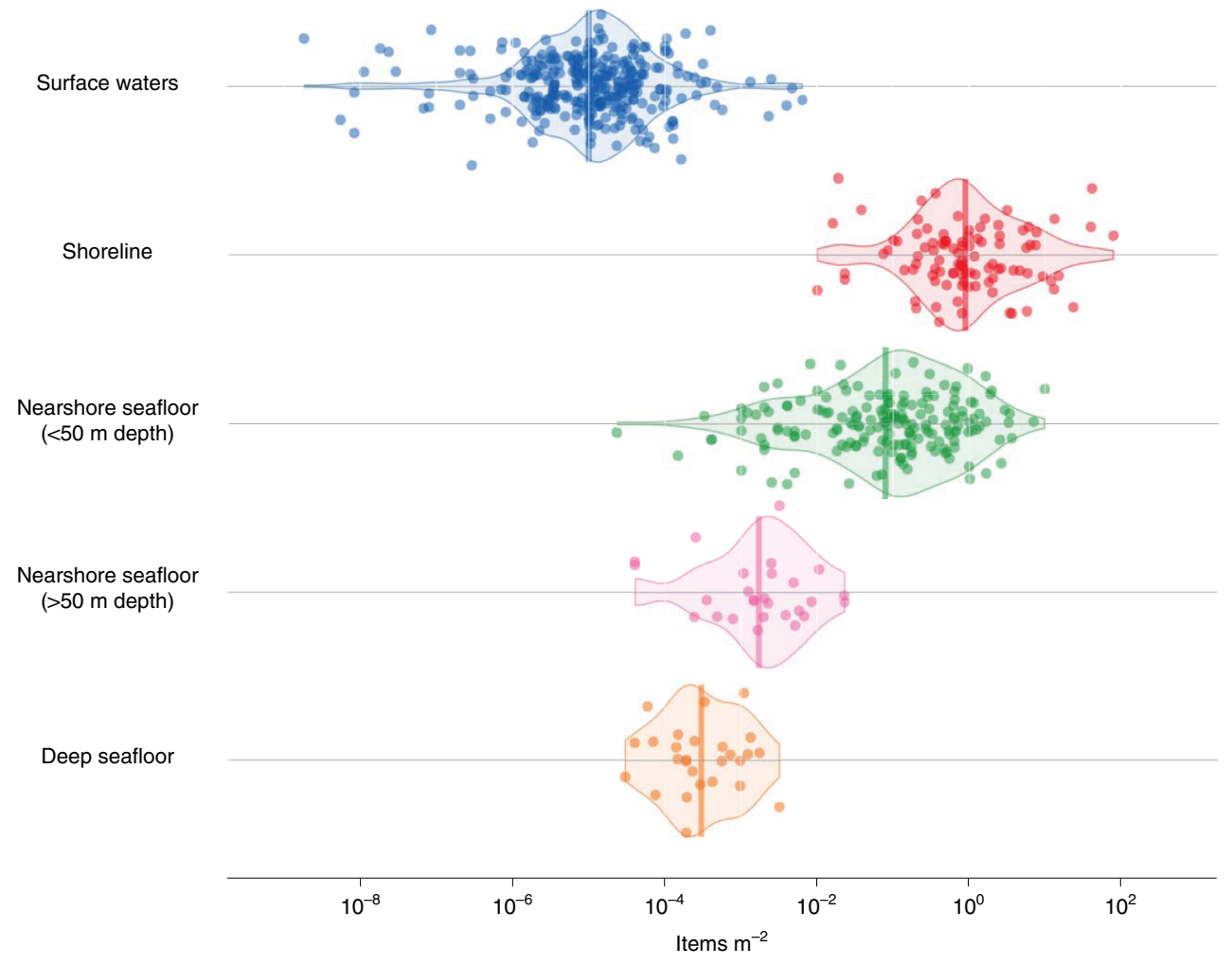

Fig. 5 | Macro-litter densities (items $\mathrm{m}^{-2}$ ) in ocean surface waters, shorelines, shallow ( $<50 \mathrm{~m}$ depth) and deep ( $>50 \mathrm{~m}$ depth) nearshore seafloor, and deep seafloor (>100 m depth). Bean density plots show individual measurements per environment as dots, the median as a vertical thick line and the 10th, 25th, 75th and 90th percentiles as white lines. The graph compiles individual measurements reported in previously published reviews covering marine environments worldwide ${ }^{38,49,50]}$. The analysis is aimed at showing order-of-magnitude differences in density of macro-litter items between environments.

of litter close to the neutral buoyancy remains a potentially important pathway of transport. Before getting deposited on the seafloor, neutrally buoyant litter may well travel for a long period in the water column, which is a poorly sampled environment compared with shores, the seafloor and the ocean surface. Thus, although we observed that the film-type items were predominantly tied with nearshore zones, a subsurface transport of macro-litter to offshore areas might occur with, for example, biofouled bags.

\section{Coastal areas as the major sink for macro-litter}

The coastal trapping of buoyant macro-litter, along with the coastal deposition of land-sourced items made of non-buoyant materials, makes the nearshore seafloor the most likely sink for macro-litter. Although there are still no consistent quantitative mass measurements across environments to scale the stocks of litter in the ocean, macro-litter density data scattered over the world support this reasoning (Fig. 5). Our analysis of macro-litter densities on the seafloor depict a sharp increasing trend from deep to shallow areas, reaching the order of one item per ten square metres on the seafloor area closest to shore, akin only to those concentrations measured along the shoreline.

Using the nearshore-seafloor reservoir to explore geographical patterns in litter composition, we noted that the prevalence of single-use items was apparent at more densely inhabited latitudes $\left(50^{\circ} \mathrm{N}\right.$ to $30^{\circ} \mathrm{S}$; Supplementary Fig. 7), but their proportion decreased outside this latitudinal band, where the share of fishing-related items increased. The share of single-use plastic also decreased in the socioeconomic regions with the highest gross domestic product (GDP) per capita (Fig. 6 and Supplementary Fig. 8). Both a small population and high GDP are associated with low waste inputs from land into the ocean ${ }^{4}$. Thereby, we found a lower fraction of single-use plastic litter relative to fishing gear in areas where lower waste loading is predicted. In addition, the persistence of litter resulting from fishing activity identifies this sector as a special target to effectively manage marine plastics globally, a proposal in line with the estimates of fishing-gear loss across the world (from $6 \%$ to $29 \%$ per year depending on gear type $)^{13}$.

\section{Recommendations}

Our study reveals that land-based waste inputs are routed mainly to shore and nearshore areas, while open-ocean surface accumulations are closely related to fishing and shipping activities that eventually transfer litter to the deep seafloor. Nearshore environments emerge as key areas to intercept micro-plastic loads due to their function as a temporary reservoir, which supplies small-sized plastic fragments that spread over the open ocean.

Overall, eight out of ten macro-litter items were made of plastic. The combination of irresponsible production of single-use plastic goods, inappropriate behaviour by end users and flaws in recovery systems has resulted in disproportionate leakage of plastic items to nature. This input, together with the persistence of plastic materi$\mathrm{als}^{20}$, may explain the overwhelming prevalence of plastic in the ocean (Fig. 1). Relevant action plans against plastic are already in force; however, market-restriction actions often focus on superfluous or easily replaceable items such as single-use straws, cotton buds and drink stirrers ${ }^{42,43}$. While these actions are welcome, we demonstrate here that they do not address the core problem (Fig. 2).

Single-use bags, bottles, food containers and wrappers are the four most pervasive macro-litter items (44\% of the total items across environments). Litter from take-out food and beverages is 

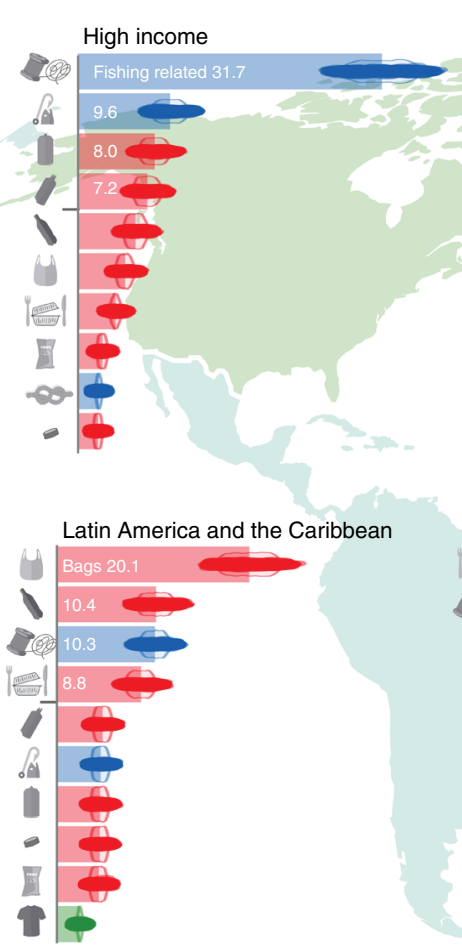
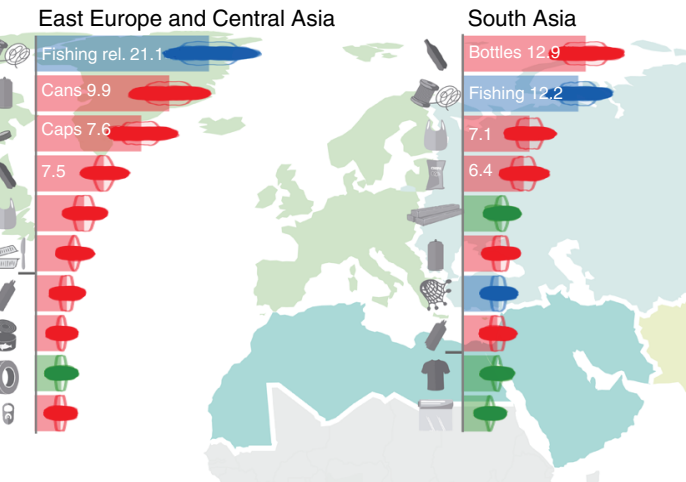

North Africa and Middle East

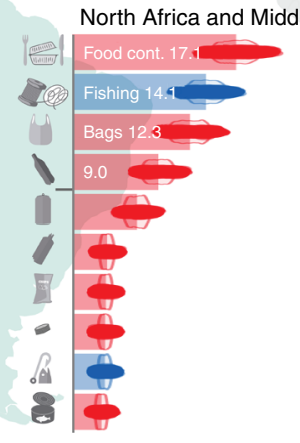

Sub-Saharan Africa

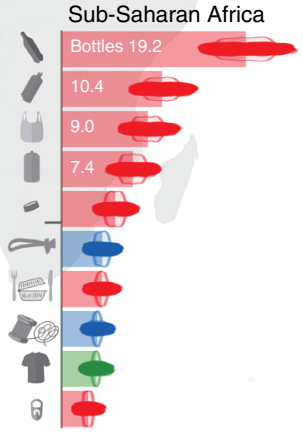

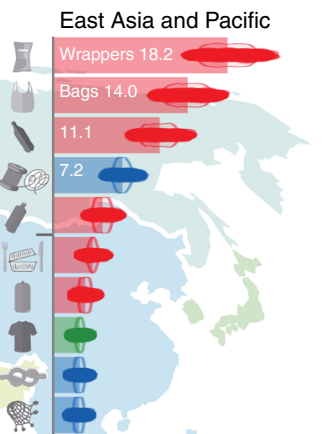

Take-out consumer

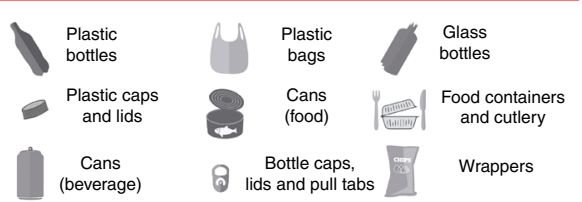

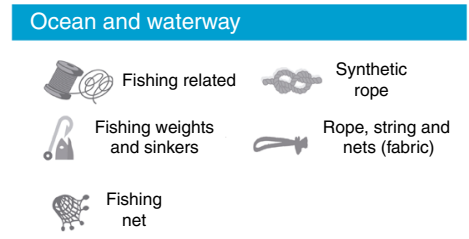

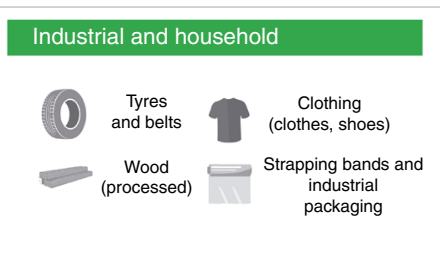

Fig. 6 | Top ten litter items in the nearshore seafloor of the seven large world socioeconomic regions. Bars show mean percentages per region; the darker-coloured areas and lines around the means show the individual data outputs $(n=10,000)$ and the distribution beanplot, respectively. Uncertainties of results were quantified through 10,000 Monte Carlo iterations in each region. Bar colour relates to potential origin. Items above the horizontal line marks in the rankings comprise, at least, $50 \%$ of the total items identified. Only identifiable items were accounted for in the rankings; high-income region $(n=247,238)$, East Europe and Central Asia $(n=3,123)$, East Asia and Pacific $(n=223,618)$, Latin America and the Caribbean ( $n=61,900)$, North Africa and Middle East $(n=44,786)$, sub-Saharan Africa $(n=8,507)$ and South Asia $(n=6,711)$.

often discarded outdoors after a short use and should be prioritized by waste management actions that aim to mitigate global litter. At least three considerations can be made in this regard. First, the strategies of replacing top polluting plastic items by similar products made of more-easily degradable materials should account for all life-cycle impacts on ecosystems, including those derived from additional requirements of energy and natural resources. Second, given that waste avoidance is the most effective way to minimize litter pollution, we advocate regulatory bans on avoidable items as the preferred action in the management of take-out items (for example, single-use bags). Finally, while a broad implementation of the extended-producer-responsibility principle is rightly considered a cornerstone of a circular economy ${ }^{44}$, our results suggest that an extended consumer responsibility on essential take-out products, such as through a deposit-refund levy ${ }^{45}$, may be justified on the basis of the extra risk of leakage to the environment of these particular products.

However, items derived from ocean activities contributed, at least, $22 \%$ of the litter, on average, across environments. Our results showing marine activities as a major source of ocean litter endorse the recent amendment to MARPOL Annex $\mathrm{V}^{46}$. This amendment includes mandatory plans and registers of on-board garbage management for a wider fraction of the international fleet. These actions could be reinforced by monitoring refuse returned to port by vessels ${ }^{47}$, improving port reception facilities or implementing an overarching flat rate for waste landed, irrespective of quantity.

Tackling marine litter pollution has become a major priority worldwide, as recognized in the United Nations Ocean Decade Challenges and the Sustainable Development Goals (SDG 14 on 'life under water' and SDG 12 on 'responsible production and consumption'). Global efforts to address this challenge yield large amounts of litter data in the form of item inventories. However, this information remains fragmented due to the differences in methods and criteria to categorize litter. Here, we provide an approach to harmonize, share and integrate plastic litter inventories across regions and environments. The analysis of item composition proved to provide a useful tool to fingerprint marine litter and identify sources and delivery pathways. The resulting insights into how plastic enters and moves in the marine environment is crucial to make progress towards a circular economy and the sustainable production and consumption of plastics and other materials contributing to marine litter.

\section{Methods}

Following a search phase for inventories of macro-litter items in aquatic environments globally, we compiled a total of 36 datasets providing counts of litter by item typology in river waters and riverbed, shoreline, nearshore waters $(<100 \mathrm{~km}$ from shoreline) and nearshore seafloor ( $<100 \mathrm{~m}$ depth, $<100 \mathrm{~km}$ from shoreline), open waters ( $>100 \mathrm{~km}$ from shoreline) and deep seafloor $(>100 \mathrm{~m}$ 
depth, $>100 \mathrm{~km}$ from shoreline) (Supplementary Table 1). All inventories meeting the classification requirements and encompassing the entire macro-litter pool without biases were included in the data compilation.

Assimilating datasets produced with different sampling techniques allowed for expanding the size and coverage of the data compilation to provide a pioneer global multi-ecosystem perspective in the analysis of the marine litter, incorporating the large volumes of information collected by citizen science programmes in rivers, beaches and shallow seafloors (Supplementary Fig. 1). Assimilating such diverse data streams poses a major challenge for the comparability and standardization of datasets using different metrics, such as counts per unit surface, volume or linear distance, which preclude absolute number comparison among environments, and even sometimes within environments. Thus, our analysis focused on relative counts of items per environment (proportion of total counts). Studies with more sampling effort and on more polluted areas, which inventoried a higher number of items, added more data to the overall count for a particular environment; therefore, those studies had more relative weight in the definition of the litter composition of that particular environment.

The standardization of datasets was provided for the harmonization of litter categories, data cleaning, the consideration of the risk of overlooking and misidentification, and the geographical bias. The steps for the standardization process are arranged in Supplementary Fig. 2 and described in the following.

Harmonization of the category list of litter items. The category lists used to classify litter items in the different environments and studies were accommodated into a joint master litter category list (JML, Supplementary Table 2), made up of a total of 130 types of products. Initially, we used a detailed master list (DML, 237 categories, Supplementary Table 2) that included all the possible litter types in the data sources compiled for the present study. Once a litter inventory was adapted to the DML, the 237 categories were aggregated into 130 to deliver the inventory in the JML format. The criteria for harmonizing litter classifications are shown in Supplementary Table 2 (downloadable as an independent file), where we show the correspondence between litter categories used by the different studies (for example OSPAR codes, United Nations Environment Programme codes) and the JML list. In addition, a tool (Excel macro) to automatically convert any litter category list into the JML is provided at the website (www.marinelitterlab.eu)

Data cleaning. Litter categories that could not be adequately classified or sampled by a method were removed from all datasets to increase the comparability of methods and analyse litter compositions across environments. First, we discarded non-identifiable items (fragments and broken pieces that cannot be associated straightaway with a particular identifiable primary object). Similarly, those items that had gone through an important degradation process, making it unfeasible to determine what the original feature was, were excluded.

The smallest macro-litter items were also discarded because they probably were not systematically sampled in all datasets. That was the case with the cigarette filters, cigar tips and any other kind of litter items smaller than $3 \mathrm{~cm}$. Regarding ropes, strings, cords and threads, we discarded those tangles and pieces smaller than $10 \mathrm{~cm}$. Thus, the smallest objects considered in our compositional analysis were the small bottle caps, about $3 \mathrm{~cm}$ in diameter.

Finally, 18 litter categories corresponding to the smallest and unidentifiable items were removed from the JML, and a total of 112 litter categories remained for the compositional analysis.

Overlooking and misidentification of litter items. The counts of litter items were treated as random variables to take into account the uncertainties and biases in the census. Therefore, ranges of counts, in which the true number of items is expected to lie, were used instead of single counts. A probability space for each $c_{l}^{e}\left(C_{l}^{e}\right)$ was defined according to the litter category, counting technique and environment as:

$$
\begin{aligned}
& C_{l}^{e}=\text { random }[\mathrm{min}, \max ]=\text { random } \\
& {\left[\left(c_{l}^{e} \times \omega^{l, e, t}\right)-\left(c_{l}^{e} \times \omega^{l, e, t}\right) \times \delta^{l, e, t},\left(c_{l}^{e} \times \omega^{l, e, t}\right)+\left(c_{l}^{e} \times \omega^{l e, t}\right) \times \delta^{l, e, t}\right]}
\end{aligned}
$$

where 'random' is a statistical function defining a uniform probability distribution of litter counts between a minimum ( $\min )$ and a maximum (max); $\delta^{l, e, t}$ and $\omega^{l, e, t}$, respectively, account for the uncertainty and potential bias in the counting of the litter category $l$ sampled from the technique $t$ in the environment $e ; \delta^{l, e, t}$ corresponds to the relative uncertainty, expressed as a decimal fraction of the measurement that could be uncertain; $\omega^{l, e, t}$ is a weighting factor applied on the counts of some difficult-to-detect items. Therefore, the limits for the probability space of litter counts results from adding and subtracting $\left(c_{l}^{e} \times \omega^{l, e, t}\right) \times \delta^{l, e, t}$ to/ from the weighted measurement $\left(c_{l}^{e} \times \omega^{l, e, t}\right)$.

The smallest items were removed from the inventories to enable the comparability of relative compositions; however, some of the litter categories considered in the present analysis may show higher risk than others of being overlooked or misidentified. Among the difficult-to-detect items (DDIs), we identified bottles caps $(\sim 3 \mathrm{~cm}$ in diameter), lolly and cotton-bud sticks $(\sim 8 \mathrm{~cm}$ in length; $\sim 0.2 \mathrm{~cm}$ in diameter), stirrers and straws ( $>10 \mathrm{~cm}$ in length; $\geq 0.5 \mathrm{~cm}$ in diameter) and fishing threads $\left(>10 \mathrm{~cm} ; \sim 0.1 \mathrm{~cm}\right.$ in diameter). $\delta^{l, e, t}$ was, at least,
$20 \%$ and reached up to $53 \%$ for the DDIs; $\omega^{l, e, t}$ was equal to 1 for most of the litter items, and it ranged from 1.05 to 1.26 for the DDIs. The justification and detailed description of the parameters $\left(\delta^{l, t,}, \omega^{l, e, t}\right)$ used to consider the risk of overlooking and misidentification in the countings are shown in Supplementary Methods and Supplementary Table 2 .

Geographical bias in the samplings. Datasets within the same environment were processed to account for the geographical sampling bias before developing the global rankings of items. Thus, litter counts per environment were pooled into seven world socioeconomic regions ${ }^{48}$ : a high-income region (HI), East Europe and Central Asia (EECA), South Asia (SA), East Asia and Pacific (EAP), Latin America and Caribbean (LAC), Middle East and North Africa (MENA), and sub-Saharan Africa (SSA). The division of the world countries into these seven regions included geographical, cultural and economic criteria (for example, GDP constant US $\$_{2010}$ averaged for the years 2010-2016) ${ }^{48}$. Other classifications add emerging countries as Chile, Qatar, Guam and others to the HI region. However, we opted to include in the HI region only countries with a high socioeconomic level over the long term (mature high-income countries) as the implementation of infrastructure for waste recovery requires long timescales. We note that litter counts in offshore environments were pooled into a single global region due to the inability to apportion the inventories to specific countries.

Mathematically, the proportion of the litter category $l$ for the environment $e$ in the region $r\left(X_{l}^{e, r}\right)$ was calculated as:

$$
X_{l}^{e, r}=\frac{C_{l}^{e, r}}{\sum_{l=1}^{112} C_{l}^{e, r}}
$$

where $C_{l}^{e, r}$ is the probability distribution of the count of items belonging to $l$ in all inventories in $e$ and $r$. The proportion of the litter category $l$ for the environment $e$ at the global scale $\left(X_{l}^{e}\right)$ combines the counts from the seven regions as follows:

$$
X_{l}^{e}=\frac{\sum_{r=1}^{7} \mathrm{mw}^{r} \times X_{l}^{e, r}}{\sum_{r=1}^{7} \mathrm{mw}^{r}}
$$

where $\mathrm{mw}^{r}$ is the mismanaged waste generated from the region $r$ as defined by Jambeck et al. ${ }^{4}$.

Monte Carlo simulations. Uncertainty in the litter counts was propagated to the top-item rankings through Monte Carlo simulations. Following equation (1), we started by generating a random count for each litter category within the minimum and maximum defined by $\delta^{l, e, t}$ and $\omega^{l, e, t}$. Then, we proceed applying equations (2) and (3) to the generated dataset to derive a global litter ranking for each environment. This process was repeated for a total of 10,000 random sets of litter counts. The end result was 10,000 global rankings for each of the study environments. The dispersion of the outputs was graphed as 'beanplots' to show the effect of the uncertainty on the global rankings. In the case of the nearshore seafloor, litter rankings were also analysed at the regional level (equation (2) and Fig. 6) since this environment showed the most spatially extensive sampling coverage and is where the highest macro-litter loads are expected.

Nature and origin of the litter. In addition to the analysis of the litter composition per item type, we classified the litter according to material, shape and possible provenance (Fig. 1). Each of the JML categories was associated with a specific material type, including plastic, rubber, textile, paper, wood, metal, glass and ceramics, and others. For those items categorized as 'plastic material', an additional classification into rigid (thick-walled) plastic, film-type (flexible, thin membranes) plastic and line (string/cord type) was carried out. Moreover linkages were established between litter categories related to their provenance: take-out consumer activity (outdoor consumption of convenience food, shopping); ocean and waterway (fishing, aquaculture, shipping); industrial and household; smoking-related; and medical/personal hygiene. The associations between particular litter items and material, plastic type and provenance are described in Supplementary Table 4.

Flow chart of top litter items in the ocean. The main ocean pathways were depicted for the most abundant litter items found: (1) bags, (2) plastic bottles, (3) food containers and cutlery, (4) plastic wrappers, (5) synthetic ropes, strings, cords threads and nets, (6) beverage cans, (7) glass bottles, (8) plastic caps and lids, and (9) industrial packaging. First, a flow chart with all possible connections between environments was designed according to two main gravitational flow directions, from the elevated inland zones to the deep offshore zones, and a vertical flow from surface to depths in the water column (Supplementary Fig. 6). In addition, we consider potential landward and seaward flows of floating macro-litter between neighbouring environments at the surface level (shoreline, nearshore and open waters). Thus, all flows were assumed to be unidirectional with the exception of those between shoreline and nearshore waters and between nearshore and open waters. Four main entrances of litter to the aquatic environments were accounted for: inland inputs, shoreline inputs, nearshore inputs and offshore inputs from high-sea activities. 
For each litter item, the connection between environments was set as relevan and finally drawn in the flow chart if the item contributed at least $5 \%$ to the total litter abundance in the reservoirs linked, both source and sink. Moreover, if the share of the item in the receiving environment was higher than $10 \%$, the connector was graphed with a thick line, indicating a relatively important flow for the litter load in the reservoir.

Size distribution of plastics in nearshore and open waters. The size distribution of floating plastic debris was measured in nearshore and offshore waters to test the proposed sorting mechanism by size between these two environments. The size distribution of offshore floating plastics was reported by Lebreton et al. ${ }^{8}$. Samplings were carried out in the North Pacific Gyre from July to September 2015 by simultaneously combining surface-trawling plankton nets $(0.5 \mathrm{~mm}$ square mesh, $90 \mathrm{~cm} \times 15 \mathrm{~cm}$ mouth) and macro-nets $(1.5 \mathrm{~cm}$ square mesh, $6 \mathrm{~m} \times 1.5 \mathrm{~m}$ mouth) to cover the 'full' size spectrum of plastics, from fragments of $0.5 \mathrm{~mm}$ to items up to $1 \mathrm{~m}$ in length. Plastic debris was classified according to typology (rigid, film and lines) and size $(>0.05 \mathrm{~mm},>0.15 \mathrm{~mm},>1.5 \mathrm{~cm},>5 \mathrm{~cm},>10 \mathrm{~cm}$, $>50 \mathrm{~cm}$ ). These sampling and analysis strategies were replicated in October 2017 in nearshore waters of the southwestern Mediterranean, along $270 \mathrm{~km}$ of the Spanish coastline. Surface-trawling plankton nets $(0.2 \mathrm{~mm}$ square mesh, $82 \mathrm{~cm} \times$ $130 \mathrm{~cm}$ mouth) and macro-nets $(1.5 \mathrm{~cm}$ square mesh in the cod end, $2.5 \mathrm{~m} \times 0.77 \mathrm{~m}$ mouth) were also combined to sample small and large plastics, respectively. For small plastics, the plankton net was higher $(130 \mathrm{~cm}$ versus $15 \mathrm{~cm})$ and the mesh was finer $(0.2 \mathrm{~mm}$ versus $0.5 \mathrm{~mm})$ than those used in offshore waters. In addition, wind speed was slightly lower in the nearshore sampling than in the offshore samplings $(9.0 \pm 5.9$ knots and $12.6 \pm 4.4$ knots, respectively). Hence, it is possible to assert that the surface concentrations of micro-plastics in the nearshore waters were not underestimated in relation to offshore waters due to surface mixing or an inefficient capture of particles.

First-order approximation of the density of macro-litter items in ocean environments. To examine the order-of-magnitude differences between the main depositional environments, we compiled data from all over the world and graphed it as 'beanplots'. The ocean seafloor was divided into shallow $(<50 \mathrm{~m}$ depth) nearshore seafloor, deep ( $>50 \mathrm{~m}$ depth) nearshore seafloor and deep seafloor ( $>100 \mathrm{~m}$ depth). The ocean surface and the shoreline were also included in data compilation. To avoid 'cherry picking', data sources were limited to the cross-ecosystem review by Galgani et al. ${ }^{1}$ and the studies referred therein, amended with the reviews by Pham et al. ${ }^{38}$ and Consoli et al. ${ }^{49}$ to increase the data coverage in the seafloor. Raw measurements of macro-litter density per surface were used as reported in the original studies.

Reporting Summary. Further information on research design is available in the Nature Research Reporting Summary linked to this article.

\section{Data availability}

Supplementary text and additional figures and tables can be found in the supplementary material. The data that support the findings of this study, as well as a tool (Excel macro) to automatically convert any litter category list into the joint master list (JML) used here, are available at https://marinelitterlab.eu/ and from the corresponding authors upon request.

Received: 28 May 2020; Accepted: 15 April 2021; Published online: 10 June 2021

\section{References}

1. Galgani, F., Hanke, G. \& Maes, T. in Marine Anthropogenic Litter (eds Bergmann, M. et al.) 29-56 (Springer, 2015).

2. Crippa, M. et al. A Circular Economy for Plastics: Insights from Research and Innovation to Inform Policy and Funding Decisions (European Commission, 2019).

3. Weideman, E. A., Perold, V., Arnold, G. \& Ryan, P. G. Quantifying changes in litter loads in urban stormwater run-off from Cape Town, South Africa, over the last two decades. Sci. Total Environ. 724, 138310 (2020).

4. Jambeck, J. R. et al. Plastic waste inputs from land into the ocean. Science 347, 768-771 (2015).

5. Cózar, A. et al. Plastic debris in the open ocean. Proc. Natl Acad. Sci. USA111, 10239-10244 (2014).

6. Eriksen, M. et al. Plastic pollution in the world's oceans: more than 5 trillion plastic pieces weighing over 250,000 tons afloat at sea. PLOS ONE 9, e111913 (2014).

7. van Sebille, E. et al. A global inventory of small floating plastic debris. Environ. Res. Lett. 10, 124006 (2015)

8. Lebreton, L. et al. Evidence that the Great Pacific Garbage Patch is rapidly accumulating plastic. Sci. Rep. 8, 4666 (2018).

9. Ocean Conservation 2011 Annual Report (International Ocean Conservancy, 2011).
10. Marine LitterWatch (European Environment Agency, accessed 20 April 2018); https://www.eea.europa.eu/themes/water/europes-seas-and-coasts/ assessments/marine-litterwatch/data-and-results/ marine-litterwatch-data-viewer

11. Canals, M. et al. The quest for seafloor macrolitter: a critical review of background knowledge, current methods and future prospects. Environ. Res. Lett. 16, 023001 (2021).

12. Ó Briain, O., Marques Mendes, A. R., McCarron, S., Healy, M. G. \& Morrison, L. The role of wet wipes and sanitary towels as a source of white microplastic fibres in the marine environment. Water Res. 182, 116021 (2020).

13. Richardson, K., Hardesty, B. D. \& Wilcox, C. Estimates of fishing gear loss rates at a global scale: a literature review and meta-analysis. Fish Fish. 20, 1218-1231 (2019).

14. Morritt, D., Stefanoudis, P. V., Pearce, D., Crimmen, O. A. \& Clark, P. F. Plastic in the Thames: a river runs through it. Mar. Pollut. Bull. 78, 196-200 (2014).

15. de Stephanis, R., Giménez, J., Carpinelli, E., Gutierrez-Exposito, C. \& Cañadas, A. As main meal for sperm whales: plastics debris. Mar. Pollut. Bull. 69, 206-214 (2013).

16. Gilardi, K. et al. Sea-Based Sources of Marine Litter-A Review of Current Knowledge and Assessment of Data Gaps (FAO, 2020).

17. Ryan, P. G., Dilley, B. J., Ronconi, R. A. \& Connan, M. Rapid increase in Asian bottles in the South Atlantic Ocean indicates major debris inputs from ships. Proc. Natl Acad. Sci. USA 116, 20892-20897 (2019).

18. Roman, L. et al. A global assessment of the relationship between anthropogenic debris on land and the seafloor. Environ. Pollut. 264, 114663 (2020).

19. Plastics-The Facts 2017 (Plastic Europe, 2017).

20. Andrady, A. L. in Marine Anthropogenic Litter (eds Bergmann, M. et al.) 57-72 (Springer, 2015).

21. Ryan, P. G. Does size and buoyancy affect the long-distance transport of floating debris? Environ. Res. Lett. 10, 84019 (2015).

22. Lebreton, L., Egger, M. \& Slat, B. A global mass budget for positively buoyan macroplastic debris in the ocean. Sci. Rep. 9, 12922 (2019).

23. Maximenko, N., Hafner, J. \& Niiler, P. Pathways of marine debris derived from trajectories of Lagrangian drifters. Mar. Pollut. Bull. 65, 51-62 (2012).

24. Lebreton, L.-M., Greer, S. D. \& Borrero, J. C. Numerical modelling of floating debris in the world's oceans. Mar. Pollut. Bull. 64, 653-661 (2012).

25. Van Sebille, E., England, M. H. \& Froyland, G. Origin, dynamics and evolution of ocean garbage patches from observed surface drifters. Environ. Res. Lett. 7, 44040 (2012).

26. Yoon, J.-H., Kawano, S. \& Igawa, S. Modeling of marine litter drift and beaching in the Japan Sea. Mar. Pollut. Bull. 60, 448-463 (2010).

27. Isobe, A. et al. Selective transport of microplastics and mesoplastics by drifting in coastal waters. Mar. Pollut. Bull. 89, 324-330 (2014).

28. Kukulka, T., Proskurowski, G., Morét-Ferguson, S., Meyer, D. W. \& Law, K. L. The effect of wind mixing on the vertical distribution of buoyant plastic debris. Geophys. Res. Lett. 39, L07601 (2012).

29. Reisser, J. et al. The vertical distribution of buoyant plastics at sea: an observational study in the North Atlantic Gyre. Biogeosciences 12, 1249-1256 (2015).

30. Polasek, L. et al. Marine debris in five national parks in Alaska. Mar. Pollut. Bull. 117, 371-379 (2017).

31. Ko, C.-Y. et al. Monitoring multi-year macro ocean litter dynamics and backward-tracking simulation of litter origins on a remote island in the South China Sea. Environ. Res. Lett. 13, 44021 (2018).

32. Maximenko, N., Hafner, J., Kamachi, M. \& MacFadyen, A. Numerical simulations of debris drift from the Great Japan Tsunami of 2011 and their verification with observational reports. Mar. Pollut. Bull. 132, 5-25 (2018).

33. Egger, M. et al. A spatially variable scarcity of floating microplastics in the eastern North Pacific Ocean. Environ. Res. Lett. 15, 114056 (2020).

34. Olivelli, A., Hardesty, B. D. \& Wilcox, C. Coastal margins and backshores represent a major sink for marine debris: insights from a continental-scale analysis. Environ. Res. Lett. 15, 074037 (2020).

35. Pedrotti, M. L. et al. Changes in the floating plastic pollution of the Mediterranean Sea in relation to the distance to land. PLOS ONE 11, e0161581 (2016)

36. Efimova, I., Bagaeva, M., Bagaev, A., Kileso, A. \& Chubarenko, I. P. Secondary microplastics generation in the sea swash zone with coarse bottom sediments: Laboratory experiments. Front. Mar. Sci. 5, 313 (2018).

37. Lavers, J. L. \& Bond, A. L. Exceptional and rapid accumulation of anthropogenic debris on one of the world's most remote and pristine islands. Proc. Natl Acad. Sci. USA 114, 6052-6055 (2017).

38. Pham, C. K. et al. Marine litter distribution and density in European seas, from the shelves to deep basins. PLoS ONE 9, e95839 (2014).

39. Tubau, X. et al. Marine litter on the floor of deep submarine canyons of the northwestern Mediterranean Sea: the role of hydrodynamic processes. Prog. Oceanogr. 134, 379-403 (2015). 
40. van Sebille, E. et al. The physical oceanography of the transport of floating marine debris. Environ. Res. Lett. 15, 023003 (2020).

41. Barboza, L. G. A. et al. in World Seas: An Environmental Evaluation Vol. 3 (ed. Sheppard, C.) Ch 17 (Elsevier, 2018).

42. Directive (Eu) 2019/904 of the European Parliament and of the Council of 5 June 2019 on the Reduction of the Impact of Certain Plastic Products on the Environment (European Council, 2019).

43. The Environmental Protection (Plastic Straws, Cotton Buds and Stirrers) (England) Regulations 2020 UK Draft Legislation (UK DEFRA, 2020).

44. Leal Filho, W. et al. An overview of the problems posed by plastic products and the role of extended producer responsibility in Europe. J. Clean. Prod. 214, 550-558 (2019).

45. Hogg, D. et al. Options and Feasibility of a European Refund System for Metal Beverage Cans Final Report (Publications Office of the European Union, 2011).

46. Guidelines for the Implementation of MARPOL Annex $V$ (International Maritime Organization, 2017); http://www.imo.org/en/OurWork/ Environment/PollutionPrevention/Garbage/Documents/MEPC.295\%2871\%29. pdf

47. Ryan, P. G., Pichegru, L., Perold, V. \& Moloney, C. L. Monitoring marine plastics-will we know if we are making a difference? S. Afr. J. Sci. 116 7678 (2020).

48. Data Bank (World Bank, accessed 20 April 2018); http://databank.worldbank. org/data/home.aspx

49. Consoli, P. et al. Characterization of seafloor litter on Mediterranean shallow coastal waters: evidence from Dive Against Debris ${ }^{\star}$, a citizen science monitoring approach. Mar. Pollut. Bull. 150, 110763 (2020).

\section{Acknowledgements}

This work has been financed by the Spanish Ministry of Science, Innovation and Universities, CTM2016-77106-R, AEI/FEDER/UE through the MIDaS project. The 2014-2020 ERDF Operational Programme and the Regional Government of Andalusia (ref. FEDER-UCA18-107828, PLAn project) supported C.M.-C., and the BBVA
Foundation (PLASTREND project) supported D.G.-F.. The European Research Council (ERC) under the European Union's Horizon 2020 research and innovation programme (grant agreement no_715386) supported E.v.S. This study is the outcome of the huge labour of many dedicated volunteers and researchers who have cleaned and recorded litter all around the world together with ECOPUERTOS, Marine Litter Watch, Ocean Conservancy, Project Aware, The Great Canadian Shoreline Cleanup, The Ocean Cleanup and RIMMEL. The icons displayed in the figures were originally provided by Surfrider Foundation Europe. Thanks to A. L. Fanning for valuable comments on the document.

\section{Author contributions}

C.M.-C. and A.C. conceived and drafted the present study; they contributed equally to the work. A.C., D.G.-F., H.P.-R., J.I.G.-G., E. Montero, G.M.A., G.H., O.C.B., N.M., L.L., T.v.E. and C.I. participated in the design and coordination of the field surveys. C.M.-C., J.V., A.C., E. Martí and D.G.-F. analysed the data. All authors read and commented on the manuscript.

\section{Competing interests}

The authors declare no competing interests.

\section{Additional information}

Supplementary information The online version contains supplementary material available at https://doi.org/10.1038/s41893-021-00720-8.

Correspondence and requests for materials should be addressed to C.M.-C. or A.C.

Peer review information Nature Sustainability thanks Lauren Roman and the other, anonymous, reviewer(s) for their contribution to the peer review of this work.

Reprints and permissions information is available at www.nature.com/reprints.

Publisher's note Springer Nature remains neutral with regard to jurisdictional claims in published maps and institutional affiliations.

(c) The Author(s), under exclusive licence to Springer Nature Limited 2021 


\section{Reporting Summary}

Nature Research wishes to improve the reproducibility of the work that we publish. This form provides structure for consistency and transparency in reporting. For further information on Nature Research policies, see our Editorial Policies and the Editorial Policy Checklist.

\section{Statistics}

For all statistical analyses, confirm that the following items are present in the figure legend, table legend, main text, or Methods section.

n/a Confirmed

$\square \bigotimes$ The exact sample size $(n)$ for each experimental group/condition, given as a discrete number and unit of measurement

Х $\square$ A statement on whether measurements were taken from distinct samples or whether the same sample was measured repeatedly

$\square$ The statistical test(s) used AND whether they are one- or two-sided

X $\square$ Only common tests should be described solely by name; describe more complex techniques in the Methods section.

Х $\square$ A description of all covariates tested

$\square$ \A description of any assumptions or corrections, such as tests of normality and adjustment for multiple comparisons

$\square$ A full description of the statistical parameters including central tendency (e.g. means) or other basic estimates (e.g. regression coefficient)

$\triangle$ AND variation (e.g. standard deviation) or associated estimates of uncertainty (e.g. confidence intervals)

$\bigotimes \square \begin{aligned} & \text { For null hypothesis testing, the test statistic (e.g. } F, t, r \text { ) with confidence intervals, effect sizes, degrees of freedom and } P \text { value noted } \\ & \text { Give } P \text { values as exact values whenever suitable. }\end{aligned}$

\ $\square$ For Bayesian analysis, information on the choice of priors and Markov chain Monte Carlo settings

$\bigotimes \square$ For hierarchical and complex designs, identification of the appropriate level for tests and full reporting of outcomes

Х $\square$ Estimates of effect sizes (e.g. Cohen's $d$, Pearson's $r$ ), indicating how they were calculated

Our web collection on statistics for biologists contains articles on many of the points above.

\section{Software and code}

Policy information about availability of computer code

Data collection QGis (v3.4) and Microsoft Excel (2016) were used to obtain and organize the data. Custom code to download data from an online data set to Excel in a user-friendly and filtered format is not deemed central to the conclusions and is available upon request.

Data analysis This study was conducted using Microsoft Excel (2016) and R (v. 3.6.1). For Excel we used the basic package including the "rand" function, whereas in R we used the "Pirateplot()" function from the "yarrr package" and "hclust(d, method="ward")" function for the hierarchical cluster.

For manuscripts utilizing custom algorithms or software that are central to the research but not yet described in published literature, software must be made available to editors and reviewers. We strongly encourage code deposition in a community repository (e.g. GitHub). See the Nature Research guidelines for submitting code \& software for further information.

\section{Data}

Policy information about availability of data

All manuscripts must include a data availability statement. This statement should provide the following information, where applicable:

- Accession codes, unique identifiers, or web links for publicly available datasets

- A list of figures that have associated raw data

- A description of any restrictions on data availability

All raw data will be available at the website (to be completed at acceptance). Figure 1 and Figure 5 are associated with the raw data. Custom codes are available upon request. 


\section{Field-specific reporting}

Please select the one below that is the best fit for your research. If you are not sure, read the appropriate sections before making your selection.

Life sciences

Behavioural \& social sciences

Ecological, evolutionary \& environmental sciences

For a reference copy of the document with all sections, see nature.com/documents/nr-reporting-summary-flat.pdf

\section{Ecological, evolutionary \& environmental sciences study design}

All studies must disclose on these points even when the disclosure is negative.

Study description

In this study we carried out an in-depth harmonization of sampling methods and analyzed the distribution of more than 12 million of litter items across aquatic habitats worldwide. A total of 36 data sets providing counts of litter by item typology were harmonized and combined for the present study. The items were classified by material, plastic type and probable origin of the litter found in seven major aquatic environments at global scale.

Research sample

The full database covered seven major aquatic environments globally, specifically river waters and riverbed, shoreline, nearshore waters and nearshore seafloor, open waters, and deep seafloor. Our analysis focused on the counts of items per environment (litter inventories), irrespective of whether there are estimates for the area or volume sampled. This approach allowed for expanding the size and coverage of the data set to provide a global multi-ecosystem perspective never used before in the analysis of the marine litter, specially due to the mainstreaming of the huge amount of information collected by citizen science in rivers, beaches and shallow seafloors. Data sources are provided in Table S1.

Sampling strategy

Litter sampling was performed in different ways as per table S1

Methods

Floating barriers, retention booms, stationary-point visual census on surface waters, and census of stranded litter in river banks Visual census by diving, and nets anchored to river bed

Beach cleanups

Surface trawling mega-nets and strip-transect visual census from vessels.

Surface trawling mega-nets, and strip-transect visual census from vessels.

Scuba divers

Video camera and bottom trawling nets

Data collection

Data collection varies for each of the 36 data sets used in the study. The data compilation was managed by the co-authors of the manuscript according to the different methodologies. C. Morales-Caselles and A. Cózar harmonized the collected data considering the different methodologies.

Timing and spatial scale This study contains data ranging from 2008 to 2019 at a global scale.

Data exclusions

Some data was excluded from the analysis and the criteria has been explained in the text. The data set was populated with large identifiable items, while small pieces and fragments were removed from the counts. This was the case of fragments and broken pieces that cannot be associated straightaway to a particular identifiable primary object. Those items that had gone through an important degradation process making unfeasible to determine what the original feature was, were similarly excluded. Regarding ropes, strings, cords and threads, we only considered those tangles and pieces larger than ten centimeters. The smallest object size considered in the analyses was the equivalent to a small bottle cap about $3 \mathrm{~cm}$ in diameter. Cigarette filters and cigar tips were excluded, because these small items were not systematically sampled in all data sets.

Reproducibility

The reproducibility of the analysis needs to take into account the harmonizing factors used for each single item depending on the sampling strategy shown in Table S2 (Weighing factors (fw) and confidence intervals (Cls) applied for item category and sampling method. Cls are shown through lower and upper limits determining the interval of confidence)

Randomization

The category lists used to classify litter items in the different data sets were accommodated into a joint master litter category list (JML List, Table S2), made up of a total of 112 types of products. The criteria for harmonizing litter classifications are shown in table S2 (downloadable as independent htm file), where we show the correspondence between litter categories used by the different studies (e.g., OSPAR codes, UNEP codes) and the JML List. Moreover, an Excel tool for automatically convert any major category list into the JML List is provided at website (to be released at acceptance).

The analysis did not consider non-identifiable items

Blinding

We feel that blinding is not relevant to the study of global flows of litter

Did the study involve field work? $\square$ Yes $\square$ No

\section{Reporting for specific materials, systems and methods}

We require information from authors about some types of materials, experimental systems and methods used in many studies. Here, indicate whether each material, system or method listed is relevant to your study. If you are not sure if a list item applies to your research, read the appropriate section before selecting a response. 
Materials \& experimental systems Methods

\begin{tabular}{l|l|l|l|l}
\hline Involved in the study & Involved in the study \\
$\square$ Antibodies & Eukaryotic cell lines
\end{tabular}

